\title{
Acute cervical cord injuries in patients with epilepsy
}

\author{
JW ALLEN, ${ }^{*}$ BE KENDALL, $†$ RS KOCEN, NM MILLIGAN $\ddagger$
}

From the National Hospital Chalfont Centre for Epilepsy, Chalfont St Peter ${ }^{*}$ the National Hospital for Nervous Diseases, London, $\dagger$ the Department of Neurology, Welsh National School of Medicine, Cardiff, UK.‡.

SUMMARY Seven cases with acute cervical cord lesions associated with a fit and fall, were found in approximately 500 patients with epilepsy over a period of 7 years. In all patients the epilepsy was refractory to drug therapy and six suffered tonic fits which resulted in falls and frequent head injuries. Notable radiological changes were found in the cervical spine; there was ankylosis in five, hyperostosis in four and the minimum sagittal diameter of the bony canal was less than $11 \mathrm{~mm}$ in three cases. The findings indicate that repetitive trauma may be a factor in producing bony changes in the cervical spine which put the patient at risk of cervical cord injury, especially when the spinal canal is developmentally narrow.

Fractures of vertebral bodies are common in patients with epilepsy, occurring in $15 \%$ in the series of Vasconcelos $^{1}$ and in $16 \%$ in that of Pederson. ${ }^{2}$ Although Pederson ${ }^{2}$ was unable to find a proportional relationship between the number of seizures or the presence of osteomalacia and the number of fractures, the causal relationship between crush fractures, especially of the upper dorsal vertebrae and convulsions is well established. It has, for example, been found that vertebral fractures occur in $43 \%$ of cases in which seizures were induced by metrazol. ${ }^{3}$ However, these fractures were considered to be of little clinical significance and they were not associated with neurological complications. ${ }^{45}$ We have been able to trace only two case reports of cervical cord injury associated with epileptic fits; Wu and Fritzlen ${ }^{6}$ described a Brown-Séquard syndrome due to anterior subluxation of the fourth on the fifth cervical vertebra following a generalised convulsion in a young man suffering from schistosomiasis and Agnetti et $a l^{7}$ described tetraplegia due to a postconvulsive cervical epidural haematoma in a patient with ankylosing spondylitis.

Between 1973 and 1980 we have observed seven cervical cord lesions of varying severity closely associated with a fall, usually precipitated by a known fit, in a population of approximately 500 patients with epilepsy who were resident at the Chalfont Centre for

Address for reprint requests: Dr JW Allen, National Hospital Chalfont Centre for Epilepsy, Chalfont St Peter, Gerrards Cross, Bucks SL9 0RJ, UK.

Received 27 March 1982. Accepted 6 June 1982.
Epilepsy. We have no reason to suspect that our patients differed from others with severe epilepsy and the notable incidence of cord damage may indicate that it is a more frequent complication of chronic recurrent seizures than has previously been stressed. We therefore considered that our cases merit presentation and discussion.

\section{Case histories}

Case 1, TP A 36-year-old man with a right hemiparesis since infancy developed epilepsy at the age of 8 years. The seizures were refractory and often began with paraesthesiae in the right limbs and dysphasia; in many there was sudden stiffening of the body and uncontrollable retropulsion resulting in frequent falls with head and facial injuries which had caused notable scarring. In 1973 he had been admitted to hospital after a fit and fall resulting in injury to the left side of the head when reluctance to move the left arm and leg had been documented. Recovery appeared satisfactory but from this time there had been a gradual development of neurological disability. In 1978 difficulty with use of the left limbs and intermittent urinary and faecal incontinence were noted. Examination revealed spastic weakness of the left arm and leg in addition to the right infantile hemiplegia; tendon reflexes were brisk and plantar responses were extensor. The patient was a very poor witness so that examination of sensation was unreliable. Movements of the neck were markedly limited in all planes. Plain radiographs of the spine showed cervical spondylosis. The minimal sagittal diameter of the spinal canal, developmentally $11.6 \mathrm{~mm}$ was reduced to $10.8 \mathrm{~mm}$ at $\mathrm{C} 4 / 5$ level by posterior osteophytes. There was considerable ossification under the anterior common ligament with spur formation and fusion between $\mathrm{C} 3$ and $\mathrm{T} 1$ levels (fig 1). Management was conservative. There is now severe 884 


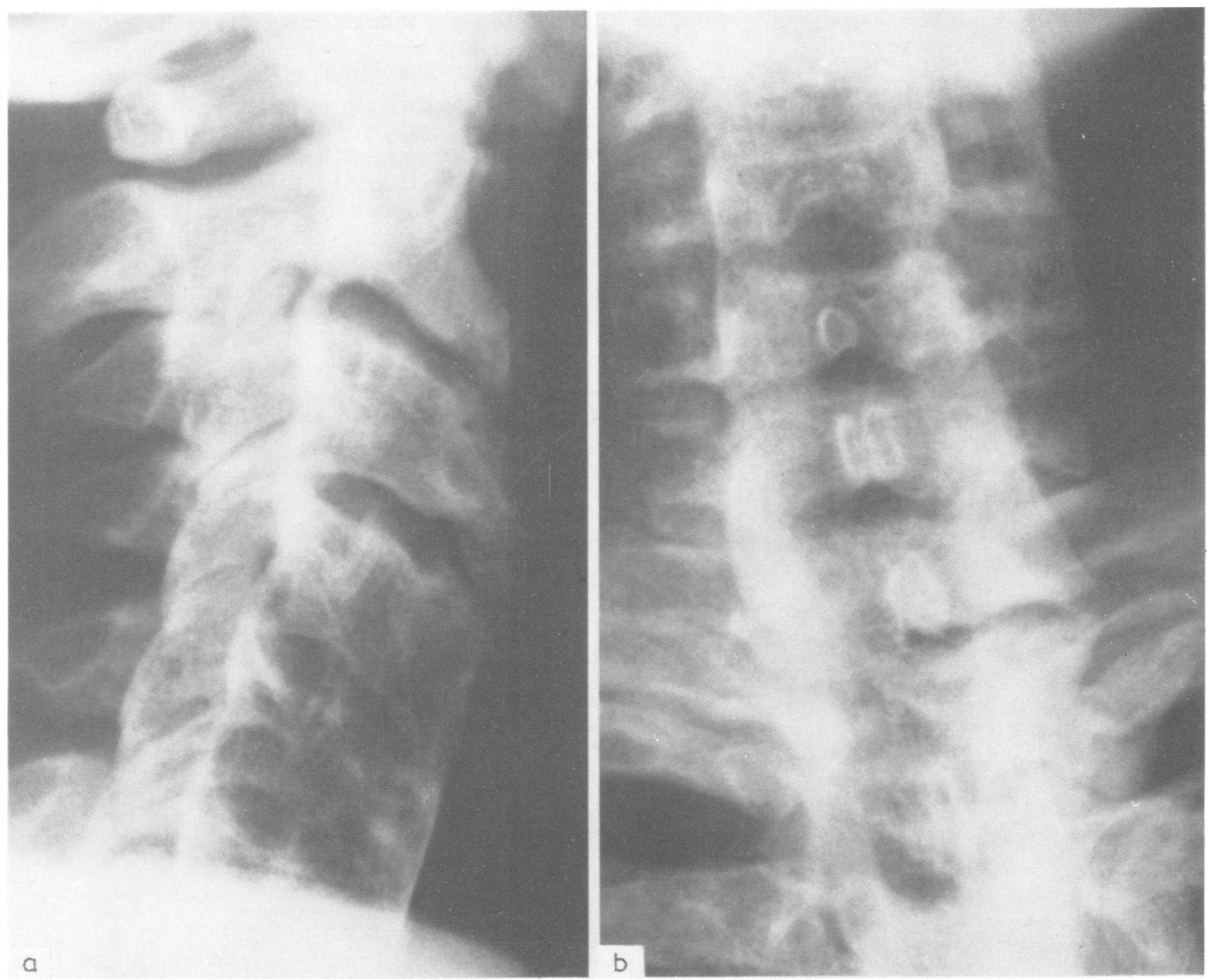

Fig 1 Case 1. Cervical Spine (a) lateral (b) postero-anterior projection. The cervical canal is narrow. Spondylosis is present at all levels and ossification under the longitudinal ligaments is fusing all the vertebrae between 3 rd cervical and the 1st thoracic levels.

disability; he is bed bound, with only enough power in the left arm to manage a special spoon for eating prepared food and bladder and bowel sensation sufficient to avoid incontinence. Plain cervical spine radiographs in 1981 showed similar abnormalities to those taken in 1978.

Case 2, GW This 28-year-old man with an infantile right hemiparesis had suffered from tonic and tonic/clonic seizures from 5 years of age. He was safely ambulant with the aid of a walking stick. In October 1979 he fell, striking the back of his head and was rendered unconscious for several minutes. Immediately on recovery he was aware of marked weakness of the left arm and leg. Examination revealed a quadriparesis more marked on the left. The left biceps jerk was absent and there was inversion of the supinator reflex; the tendon reflexes in both lower and right upper limbs were exaggerated and both plantars were extensor. Spinothalamic sensation was impaired on the right with a sensory level at C3 and the spine was tender at C3-4; sphincter control was not impaired. The physical signs were of an incomplete left sided Brown-Séquard syndrome superimposed on a congenital right hemiparesis. Plain radiographs of the spine revealed a developmentally narrow cervical canal, sagittal diameter of $12.0 \mathrm{~mm}$, reduced to $11.5 \mathrm{~mm}$ by degenerative changes at $\mathrm{C} 3 / 4$ level. Myelography showed slight protrusion of the $\mathrm{C} 3 / 4$ disc compressing the spinal cord and also minimal compression by osteophytes at $\mathrm{C} 4 / 5$ level (fig 2). He was treated with dexamethasone, a cervical collar and physiotherapy and made a full recovery.

Case 3, FW This 31-year-old man had suffered from drug resistant epilepsy since the age of 7 years. Seizures were of the tonic type with sudden stiffening and loss of consciousness which resulted in frequent falls with numerous facial injuries. In 1971 he suffered paraesthesiae in both hands and was found to be ataxic. He was investigated by air encephalography, which showed minor dilatation of the lateral ventricles, but CSF pressure monitoring for suspected hydrocephalus revealed pressures 


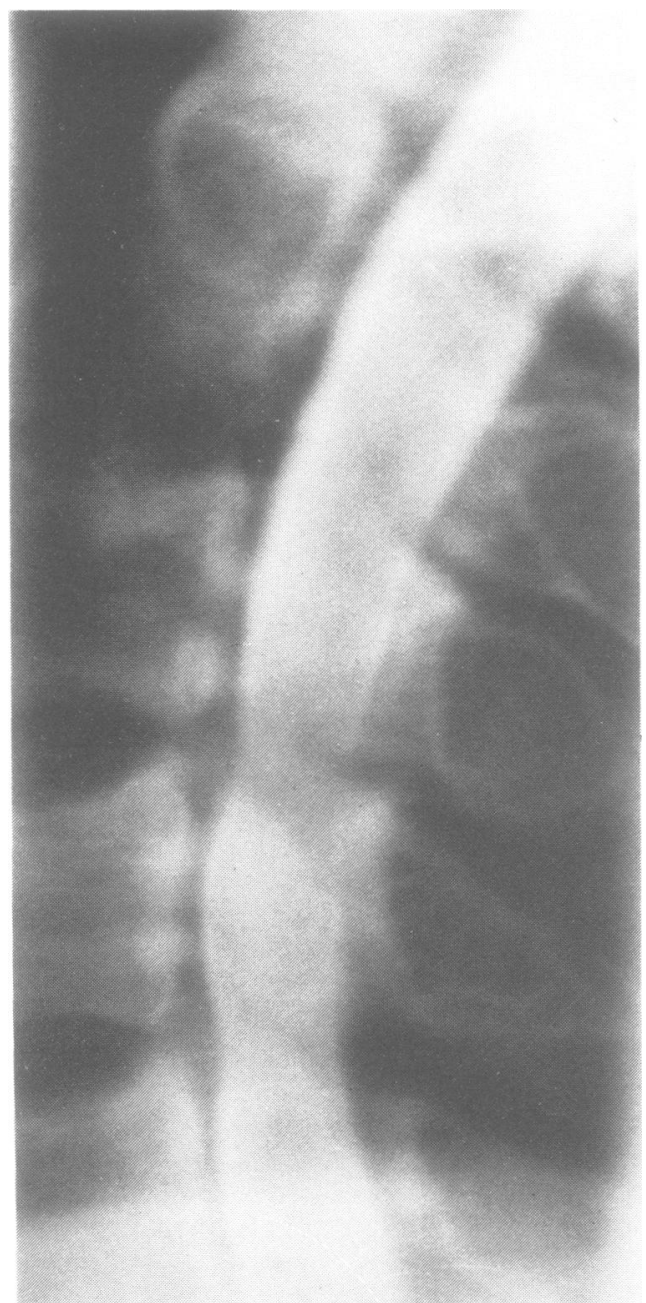

Fig 2 Case 2. Metrizamide myelogram, prone position, mid-sagittal tomogram cervical region. The cervical canal is narrow. There is slight posterior protrusion of the $\mathrm{C3/4}$ disc but it is sufficient to compress the anterior surface of the spinal cord. There is also minimal compression at C4/5 level.

in the normal range. In January 1975 he was re-investigated because of progressive ataxia of gait and a CT scan showed diffuse cerebral and cerebellar atrophy. In March 1976 he had a fit during which he fell on to his face, bruising his forehead. Several hours afterwards he developed paraesthesiae in both hands and increasing difficulty in walking, followed by urinary retention and he required catheterisation. Examination showed the facial bruising and all neck movements except flexion were painful and limited. Cranial nerves were normal. There was slight flaccid weakness of the arms and a moderate flaccid weakness of the legs. The biceps and supinator reflexes were absent bilaterally but the other tendon reflexes were normal. The abdominal reflexes were absent and both plantar responses were extensor. Vibration sense was impaired in the legs, but sensation was otherwise normal. Plain radiographs showed a developmental minimum sagittal diameter of the cervical spine of $12.5 \mathrm{~mm}$ which was reduced to $10.8 \mathrm{~mm}$ by slight posterior subluxation of C5 on C6. There was ossification under the anterior spinal ligament at C3-6 levels with fusion between $\mathrm{C} 4$ and $\mathrm{C5}$ by bridging osteophytes (fig 3 ). Myelography demonstrated flattening of the spinal cord by degenerative changes at $\mathrm{C} 5 / 6$ level (fig 4). He was managed conservatively with a cervical collar, physiotherapy and rehabilitation. He made a partial recovery and walks with a Zimmer frame, needing only minimal nursing care.

Case 4, DW A 33-year-old man had suffered epilepsy from the age of 12 years with seizures of varying but mainly tonic type. During the tonic fits he frequently fell, suffering head injuries and on two occasions he had fractured his jaw. In October 1980, during a fit, he struck his face on a wall. Shortly afterwards he was aware of heaviness in both arms and tingling in the right leg. Examination showed a large right periorbital haematoma and multiple facial scars from previous falls. Cranial nerves were normal. The left upper limb was mildly hypertonic with slight global weakness. The biceps and supinator reflexes were diminished bilaterally

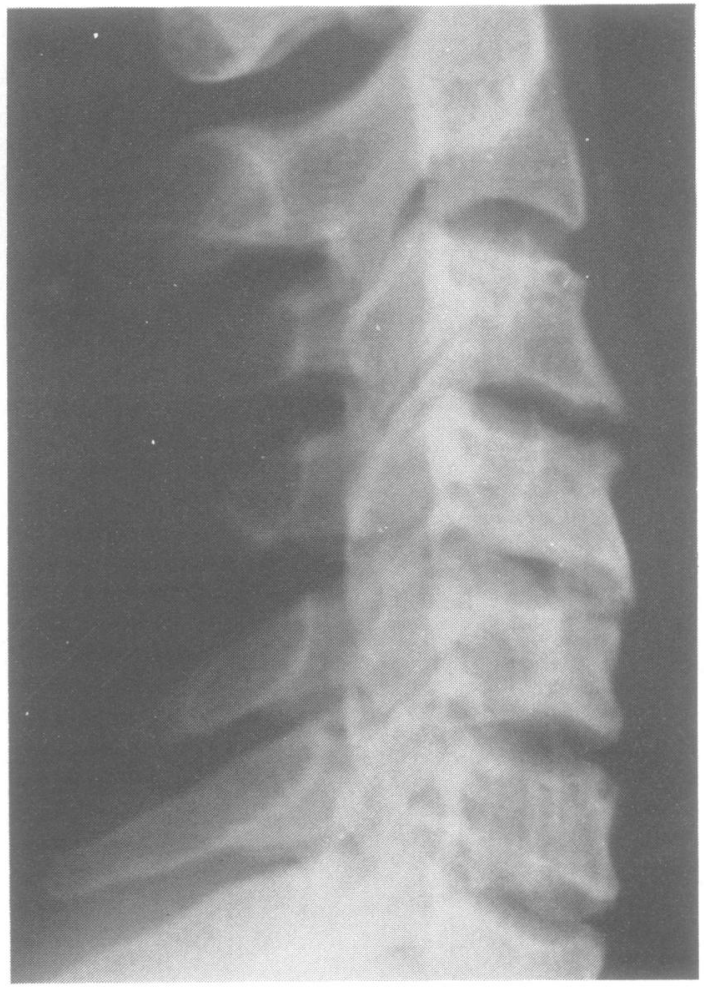

Fig 3 Case 3. Cervical spine lateral projection. There are spondylotic changes and minor posterior subluxation of $C 5$ on 6 narrows the spinal canal. There is minor ossification under the anterior common ligament at C3/6 levels with bridging osteophytes uniting $C 4$ and 5 anteriorly. 


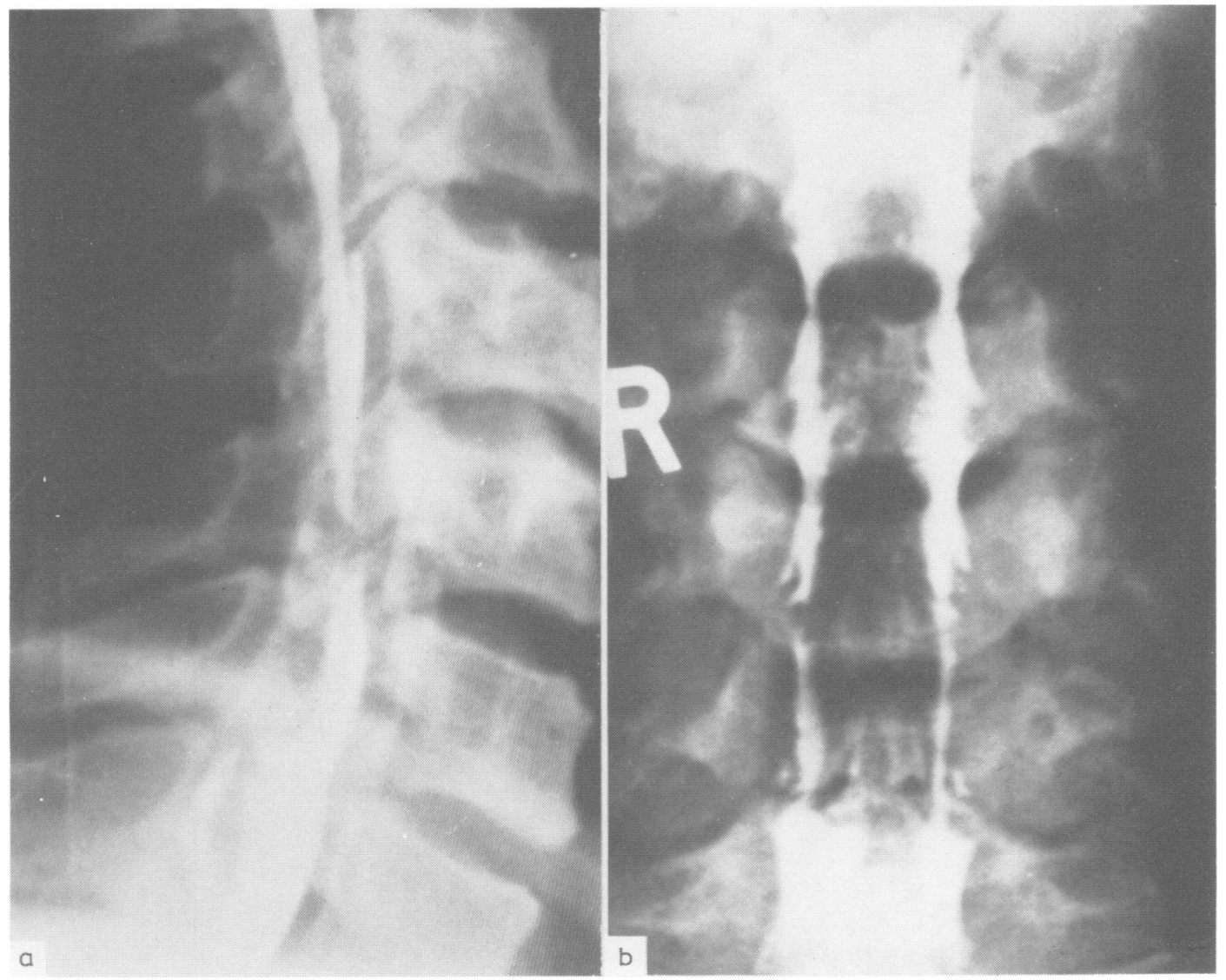

Fig 4 Case 3. Myodil myelogram prone position, (a) lateral (b) AP projection. The spinal cord is flattened by the degenerative changes at C5/6 level with increase in the transverse diameter.

and the abdominal reflexes were absent. Tone, power and tendon reflexes in the legs were normal and plantar responses were flexor. Sensation was normal. Plain radiographs showed ankylosis from C3-D1 by mature bone under the anterior and posterior longitudinal ligaments (fig 5). There was a recent horizontal fracture through the body of C5 with distraction. The sagittal diameter of the cervical canal was $13.6 \mathrm{~mm}$ and the narrowest diameter was $12.5 \mathrm{~mm}$ at $\mathrm{C} 4 / 5$ level. Management was conservative with a cervical collar and physiotherapy; he has minimal residual disability.

Case 5, DLL A 39-year-old man developed epilepsy at 16 years of age. He suffered tonic/clonic, tonic and absence seizures which were drug resistant and an episode of status epilepticus occurred in 1978. On at least two occasions he sustained fractures of the jaw as a result of falling on his chin during fits. In July 1980 he was found at the bottom of a flight of stairs with recent facial injuries presumably following a fit and fall, Several hours later he developed a rapidly progressive weakness of all four limbs and retention of urine. Examination revealed multiple facial scars and recent bruising due to his fall. The cranial nerves were normal. There was a quadriparesis with global weakness of all limbs but more marked in the legs. The tendon reflexes were normal except the biceps and supinator jerks which were diminished bilaterally. Abdominal reflexes were absent and both plantar responses were extensor. Sensation was impaired to all modalities below C5 level. Plain radiographs showed cervical spondylosis with extensive new bone formation beneath the anterior common ligament and anterior bridging at C2-D2 levels. The sagittal diameter was $15 \mathrm{~mm}$ minimum, but the narrowest diameter was $11.5 \mathrm{~mm}$ at $\mathrm{C} 4 / 5$ level. Myelography demonstrated cord flattening by osteophytes at this level (fig 6).

A laminectomy was carried out at C3-6 inclusive, followed by dexamethasone and rehabilitation. He had marked residual disability with minimal power in the limbs, urinary incontinence and faecal retention. He died suddenly in October 1980. Histological examination of the cervical cord revealed almost complete degeneration of both grey and white matter at the level of $\mathrm{C6/7}$ and the structure of the cord at that level was not recognisable. There was some ascending demyelination of the dorsal and descending demyelination of the pyramidal tracts. The appearance 


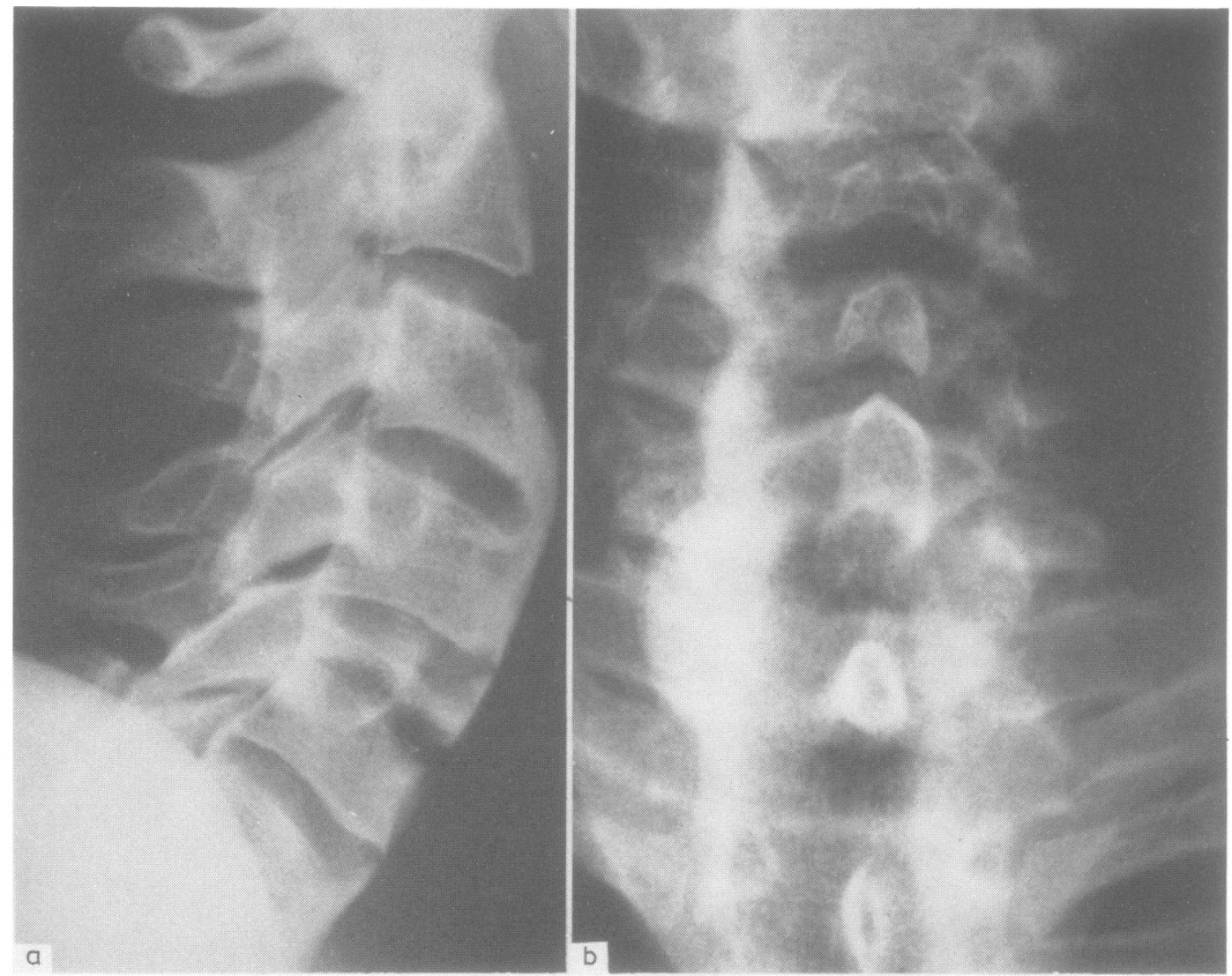

Fig 5 Case 4. Cervical spine (a) lateral (b) PA projection. There is fusion between the 3rd cervical and 1 st thoracic vertebrae by mature bone under the anterior longitudinal ligament. There is a horizontal fracture through the body of the 5 th cervical vertebra with distraction of the fragments.

was entirely consistent with the effects of a severe contusion taking place 15 months previously. Histology of the cervical spine showed degenerative changes with traumatic fragmentation of $\mathrm{C} 4 / 5$ disc; ossification was occurring in the disc cartilage and also in the ligamentous tissue with the appearances respectively of osteophytes and traction exostoses. There was no suggestion of osteomalacia.

Case 6, PL This 30-year-old man whose epilepsy started when aged 7 years suffered mainly tonic fits but also tonic/ clonic seizures and simple absences. In September 1980 he fell during a fit injuring his face and on the same day he complained of paraesthesiae and numbness in both arms. Examination revealed weakness of finger extension and of finger and thumb abduction. There was wasting of the small muscles of the hands. Knee jerks were pathologically brisk but the other tendon reflexes were normal; plantar responses were extensor. There was diminished appreciation of joint position sense and of pin prick in both hands in a pattern indicative of lower cervical root damage in addition to the cervical cord lesion. Radiographs of the spine showed a prominent cervical lordosis compensating a dorsal round back. The sagittal diameter was $16 \mathrm{~mm}$ reduced to $14 \mathrm{~mm}$ by minor spondylosis at $\mathrm{C} 5 / 6$. There was acquired fusion by anterior new bone at $\mathrm{C} 6 / 7$ level (fig 6 ). There were old crush fractures of the 9th dorsal and 3rd lumbar bodies. Management was conservative with a cervical collar and he has made a complete recovery.

Case 7, BJ A 68-year-old woman with epilepsy which started at the age of 35 years had complex partial and tonic/clonic seizures. EEG showed a right frontotemporal focus but other investigations including air encephalography and right carotid arteriography which were performed in 1968 were normal. Re-investigation in 1971 showed cortical atrophy and at this time hypothyroidism was diagnosed and was managed with thyroxin. In January 1980 she fell during a fit injuring the right side of her head. She was immediately aware of numbness in all limbs and of weakness which was more prominent in her arms, though she was able to walk with help. On examination 24 hours 


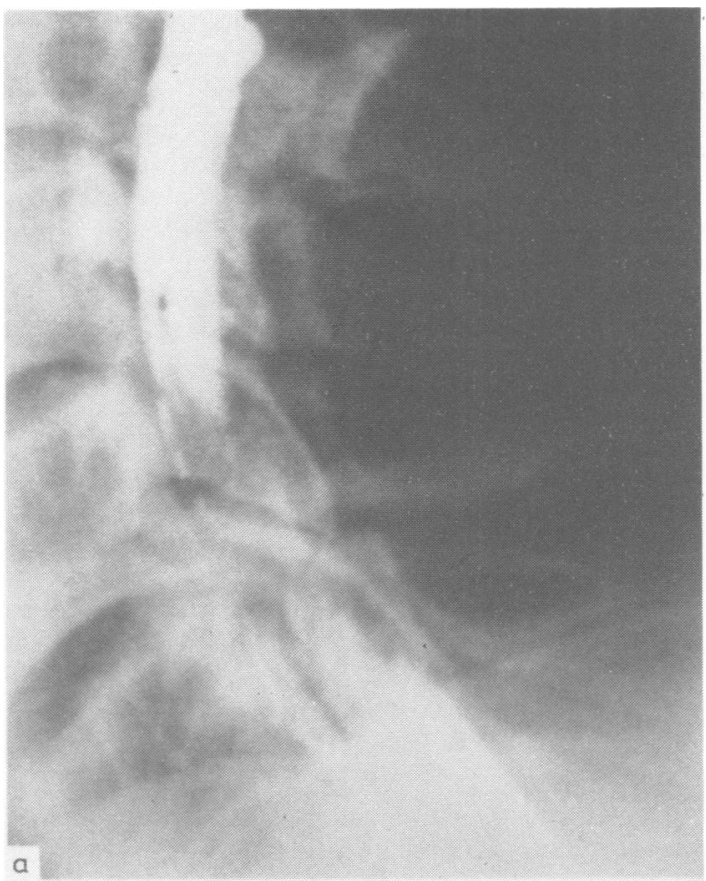

Fig 6 Case 5. Myodil myelogram prone position (a) lateral (b) antero-posterior projection. The spinal cord is flattened due to anterior compression by posterior osteophytes at C4/5 disc level.

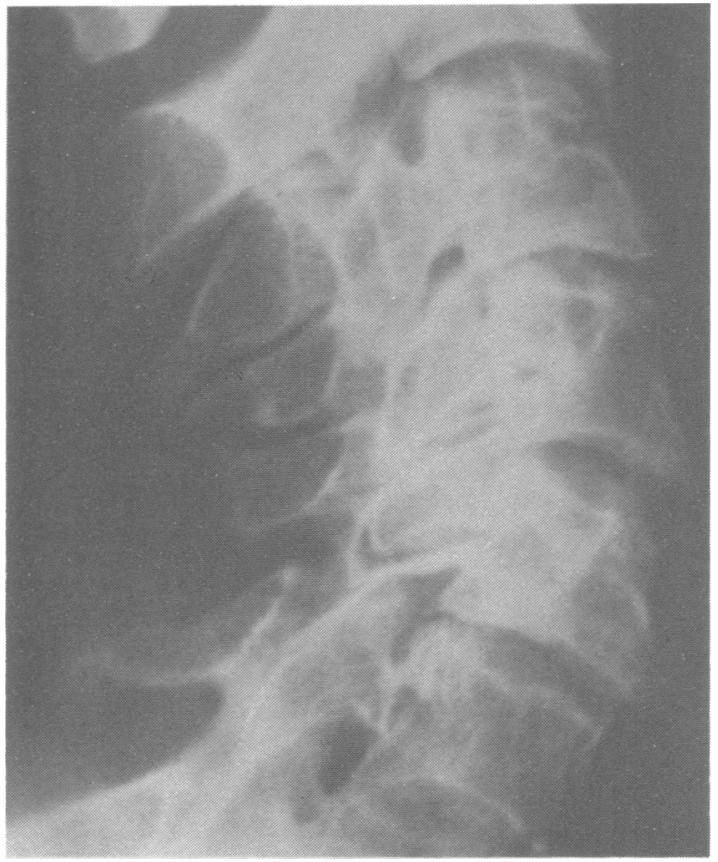

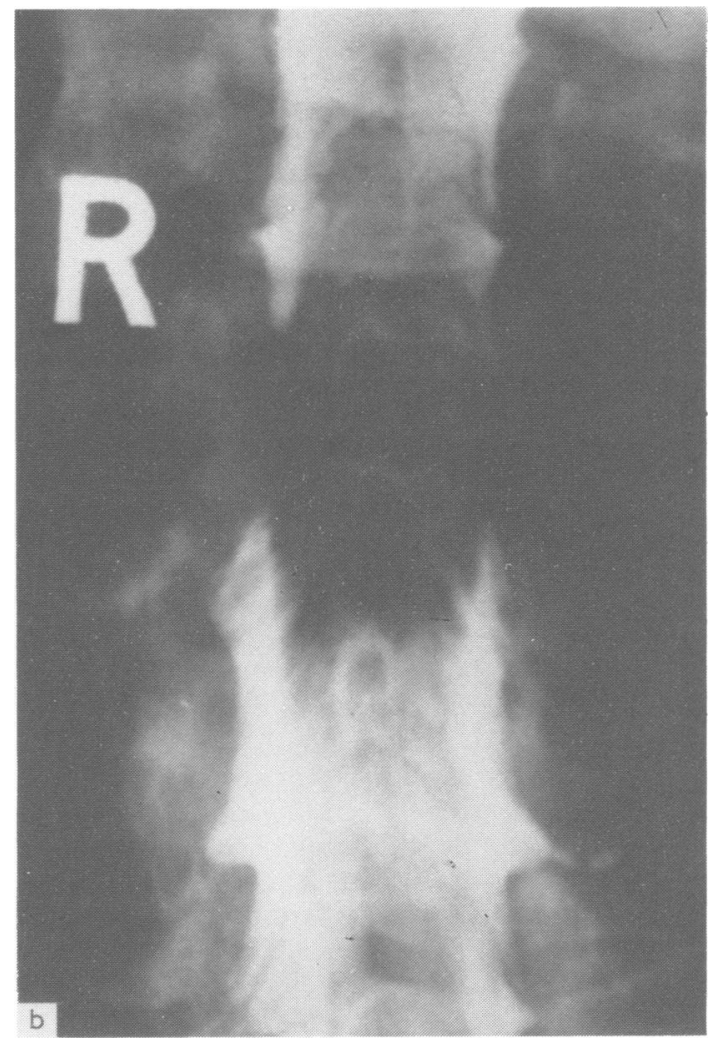

Fig 7 Case 6. 30-year-old male. Cervical spine lateral projection. There are minor spondylotic changes at all levels and bone formation under the anterior common ligament at C5-7 levels causes fusion between C6 and 7. 
later there had been considerable recovery although residual weakness was present in both arms. Tendon reflexes were pathologically brisk but the plantar responses were flexor. There was contact dysaesthesia in both hands and feet more prominently on the left side. Radiographs of the spine showed cervical spondylosis at C3-7 levels. The developmental sagittal diameter was $13 \cdot 3 \mathrm{~mm}$, reduced to $10 \cdot 8 \mathrm{~mm}$ by posterior osteophytes at $\mathrm{C} 3 / 4,5 / 6$ and $6 / 7$ levels. Management was conservative. She has made a virtually complete recovery, apart from some diminution in sensation along the ulnar border of the left hand.

\section{Comments}

The clinico-radiological features of the seven patients are summarised in table 1 . The dominance of males may reflect the sex ratio at the Chalfont Centre for Epilepsy; they were typically middle aged (mean $41 \cdot 1$ years) with a long history (mean 23.9 years) of epileptic seizures prior to the injury which had proved difficult to control. Table 2 shows that six out of the seven cases suffered from tonic fits in which the patient fell to the ground rigid; this often caused cranio-facial injuries of sufficient severity to produce considerable scarring. These injuries are likely to have subjected the cervical spine to forceful extension and, less frequently, flexion injuries. Radiographs of the spine showed cervical spondylotic changes with varying degrees of disc narrowing in six cases. The smallest developmental sagittal diameter of the bony canal of the cervical spine as reflected by the shortest distance, corrected for magnification, between the middle of a vertebral body and its conjoined lamina was $11.6-16 \mathrm{~mm}$, being below $13 \mathrm{~mm}$ in 3 cases. The corrected narrowest sagittal diameter of the bony canal at the level of degenerative changes varied between 10.8 and $14 \mathrm{~mm}$ and was below $11 \mathrm{~mm}$ in 3 cases (Nos 1, 3,7). There was round back dorsal kyphosis in several cases so that the cervical spine was held in compensatory lordosis, the position in which the sagittal diameter is minimal. There was unusually prominent ossification under the anterior common ligament causing marked anterior bone formation in four of the patients (Nos $1,3,4,5)$ and ankylosis between the bodies was present in five (Nos 1, 3, 4, 5, 6). Radiographs of other regions of the spine showed similar changes in only one patient (No 1) in whom it was confined to L5/S1 level and associated with fusion of the left sacro-iliac joint. In case 4 the hyperextension injury had caused a transverse fracture in the ankylosed segment through the body of C5.

Minor biochemical changes were noted (table 3). The corrected serum calcium levels were in the low normal range. Alkaline phosphatase was raised in all but one patient (Case 6). These findings probably reflect a degree of anticonvulsant osteomalacia and hepatic enzyme induction. No infrequently occurring tissue types were present with abnormal frequency.

Table 1 Clinicoradiological features

\begin{tabular}{|c|c|c|c|c|c|c|c|}
\hline Patient & $\begin{array}{c}T P \\
I\end{array}$ & $\begin{array}{c}G W \\
2\end{array}$ & $\begin{array}{c}F W \\
3\end{array}$ & $\begin{array}{c}D W \\
4\end{array}$ & $\underset{5}{D L L}$ & $\begin{array}{c}P L \\
6\end{array}$ & $\begin{array}{r}B J \\
7\end{array}$ \\
\hline Age years (mean 41.4) & 36 & 28 & 32 & 34 & 39 & 50 & 69 \\
\hline $\begin{array}{l}\text { Sex } \\
\text { Duration of epilepsy (mean }\end{array}$ & $\mathbf{M}$ & \multicolumn{4}{|c|}{ Duration of epilepsy (mean } & $\mathbf{M}$ & $\mathbf{F}$ \\
\hline $23.9 y r s)$ Prior to injury & 20 & 23 & 20 & 21 & 22 & 48 & 13 \\
\hline Site of craniofacial injury & Left side head & Back head & Forehead & Right forehead & Face & Face & Right side head \\
\hline $\begin{array}{l}\text { Type of neck injury } \\
\text { Time prior to }\end{array}$ & Unknown & Flexion & Extension & Extension & Extension & Extension & Unknown \\
\hline cord symptoms & 1 day & $5-10 \mathrm{mins}$ & $6-12 \mathrm{hrs}$ & $30 \mathrm{mins}$ & $6-12 \mathrm{hrs}$ & $6-12 \mathrm{hrs}$ & Immediate \\
\hline Ankylosis & + & 0 & + & + & + & + & 0 \\
\hline Hyperostosis & + & $\mathbf{0}$ & + & + & + & 0 & 0 \\
\hline Dorsal kyphosis & Marked & $\mathbf{0}$ & Slight & Marked & Slight & Slight & $\mathbf{0}$ \\
\hline Sagittal diameter mm. & & & & & & & \\
\hline Body & $11 \cdot 6$ & $12 \cdot 0$ & $12 \cdot 5$ & $13 \cdot 6$ & $15 \cdot 0$ & $16 \cdot 0$ & $13 \cdot 3$ \\
\hline Disc & $10 \cdot 8$ & $11 \cdot 5$ & $10 \cdot 8$ & $12 \cdot 5$ & $11 \cdot 5$ & $14 \cdot 0$ & $10 \cdot 8$ \\
\hline $\begin{array}{l}\text { Cervical spine movement } \\
\text { Residual disability }\end{array}$ & $\begin{array}{l}\text { very poor } \\
\text { severe }\end{array}$ & $\begin{array}{l}\text { satisfactory } \\
\text { absent }\end{array}$ & $\begin{array}{l}\text { poor } \\
\text { moderate }\end{array}$ & $\begin{array}{l}\text { very poor } \\
\text { minimal }\end{array}$ & $\begin{array}{l}\text { poor } \\
\text { severe }\end{array}$ & $\begin{array}{l}\text { satisfactory } \\
\text { absent }\end{array}$ & $\begin{array}{l}\text { satisfactory } \\
\text { minimal }\end{array}$ \\
\hline
\end{tabular}

Table 2 Number of fits/month

\begin{tabular}{|c|c|c|c|c|c|c|c|}
\hline & $\begin{array}{c}T P \\
l\end{array}$ & $\begin{array}{c}G W \\
2\end{array}$ & $\begin{array}{c}F W \\
3\end{array}$ & $\begin{array}{c}D W \\
4\end{array}$ & $\underset{5}{D L L}$ & $\begin{array}{c}P L \\
6\end{array}$ & $\begin{array}{r}B J \\
7\end{array}$ \\
\hline Tonic clonic & - & 5 & - & 1 & 1 & 1 & 1 \\
\hline Myoclonic & - & - & - & 2 & - & - & 一 \\
\hline Absence & - & - & - & - & 16 & 1 & - \\
\hline Complex partial & - & - & - & - & - & - & 2 \\
\hline
\end{tabular}


Table 3 Biochemical Findings (Means of 2 readings)

\begin{tabular}{lcccccccc}
\hline & $T P$ & $G W$ & $F W$ & $D W$ & $D L L$ & $P L$ & $B J$ & Normal \\
& 1 & 2 & 3 & 4 & 5 & 6 & 7 \\
\hline Calcium (corrected) $(\mathrm{mmol} / \mathrm{l})$ & $2 \cdot 25$ & $2 \cdot 25$ & $2 \cdot 29$ & $2 \cdot 42$ & $2 \cdot 23$ & $2 \cdot 28$ & $2 \cdot 34$ & $2 \cdot 12-2 \cdot 62$ \\
Inorganic phosphate $(\mathrm{mmol} / \mathrm{l})$ & $1 \cdot 07$ & $1 \cdot 08$ & $1 \cdot 18$ & $1 \cdot 07$ & $1 \cdot 06$ & $1 \cdot 2$ & $1 \cdot 69$ & $0 \cdot 8-1 \cdot 45$ \\
Alkaline phosphatase $(\mathrm{mU} / \mathrm{ml})$ & 106 & 105 & 120 & 177 & 93 & 58 & 134 & $38-85$ \\
\hline
\end{tabular}

The cervical cord damage was related to a particular fall in all patients. The position of facial or head trauma indicated that the precipitating injury caused cervical flexion in one case (No 2) and extension in four (Nos 3, 4, 5, 6); in two other cases the trauma was to one side of the head adding a rotational component to a probable extension injury. Case 5 was treated by decompressive laminectomy. The remainder were managed conservatively. Initial recovery occurred in all cases but this was followed by deterioration in two patients (Nos 1 and 5) who became severely disabled. Case 3 made a moderate recovery and the others were left with minimal or no residual disability.

\section{Discussion}

The exact cause of the excess bone formation in these patients is uncertain but is likely to be associated with the recurrent trauma. Penning ${ }^{8}$ cites Buetti-Baül who described cervical spondylosis in young individuals such as wrestlers and it was also noted in high-divers exposed to frequent injury to the neck. ${ }^{9}$ Some of the divers develop ossification beneath the anterior common ligament with a history of only minimal discomfort and no other disability. Excessive anterior ossification of the cervical spine has been related to a single flexion injury of the neck. ${ }^{10}$ Similar bone changes have been inconsistently observed in other patients with epilepsy who suffer recurrent head trauma without acute cord injury and in some the spine has been virtually normal so that trauma may not be the only factor in their production. No relationship to anticonvulsant medication could be shown. Although the blood biochemistry showed minimal evidence of the osteomalacia associated with anticonvulsant therapy, histological changes of osteomalacia were absent in the cervical spine of the patient who came to autopsy. The anterior hyperostosis on the vertebral body with fusion across the discs in our patients has some features similar to ankylosing hyperostosis. ${ }^{11}$ This generally asymptomatic condition occurs mainly in the elderly. In $97 \%$ of cases the dorsal region is affected but the cervical spine is involved in $78 \% .{ }^{12}$ Though the intervertebral discs are generally normal ${ }^{13}$ there may be some disc degeneration with narrowing and, rather than a disease process per se, it may be considered as "a vulnerable state in which extensive ossification results from an exaggerated response of the body in some patients to stimuli which produce only modest new bone formation in others". ${ }^{12}$ As previously noted, the remainder of the spine was not involved. Also there was no positive relationship to tissue type similar to that occurring in ankylosing spondylitis and other rheumatic conditions.

Regardless of its aetiology the increasing rigidity of the cervical spine renders it vulnerable to trauma. The fragility of the osteoporotic cervical spine of ankylosing spondylitis has been emphasised ${ }^{14}$ and $72 \%$ of spinal fractures in such cases are associated with a neurological deficit. ${ }^{15}$ Corke $^{16}$ has recently reported a similar type of fracture with neurological complications in ankylosing hyperostosis and the fracture occurring in our case 4 was of "long bone" type.

The increased rigidity of the ankylosed segment also renders the adjacent levels more liable to spondylosis and to increased angulation when subject to trauma. ${ }^{17}$ The increase in cervical lordosis caused by the presence of dorsal kyphosis also tends to increase angulation. ${ }^{18} 19$

The sagittal diameter of the cervical canal is a crucial factor in spondylotic myelopathy. Payne and Spillane $^{20}$ showed that in patients with myelopathy due to cervical spondylosis the sagittal diameter of the bony canal averaged $14 \mathrm{~mm}$, whereas in asymptomatic patients with spondylosis it measured $17 \mathrm{~mm}$. Hashimoto ${ }^{21}$ uses $10 \mathrm{~mm}$ as the absolute lower limit of normality but indicates that measurements under $12 \mathrm{~mm}$ are infrequent in normals. Alexander ${ }^{22}$ also stressed the importance of a narrow sagittal diameter in the production of myelopathy due to hyperextension injuries, noting that in five such cases the minimal diameter of the bony cervical canal was between 12 and $14 \mathrm{~mm}$. In five of the cases in our series the minimal canal diameter was less than $12 \mathrm{~mm}$. Symonds ${ }^{23}$ emphasised that both hyperflexion and hyperextension in patients with spondylosis could result in cervical cord compression and Hardy ${ }^{24}$ found that $76 \%$ of the 141 cases of cervical cord injuries in his series without fracture or dislocation had cervical spondylosis. Though $70 \%$ of Hardy's cases were over 50 years of age and most of our patients were young or middle aged, spondylosis is likely to have been accelerated by the trauma associated with recurrent seizures. In this context it 
should be noted that chronic minor trauma to the cervical spine occurring, for example, in patients with chorea athetosis and Gilles de la Tourette syndrome has resulted in cervical myelopathy. ${ }^{25}$ The type of hyperextension injury described by Taylor and Blackwood ${ }^{19}$ in which the anterior common ligament is disrupted and the cord is compressed between the posteriorly dislocating body and the neural arch of the vertebra below before the former reduced spontaneously, is not associated with any major fracture or dislocation visible on plain radiographs. This is one further mechanism capable of producing paraplegia in hyperextension injuries in patients without narrowing of the spinal canal on plain films. Hyperflexion injuries causing disc prolapse require myelography for elucidation. Since metrizamide has epileptogenic properties and seizures are particularly dangerous in the presence of cervical cord compression especial care must be exercised, particularly if a high concentration is being used above a partial or complete obstruction in the cervical region. Adequate anticonvulsant cover and monitoring of the injection to limit the volume of contrast medium to that necessary for diagnosis are, of course, routine. The mechanism of the post traumatic spinal cord injury in patients with chronic refractory epilepsy is most likely precipitated by the violent neck movement causing compression of the cord in a canal rendered narrow by premature spondylosis. Though uncommon, this condition is possibly not as rare as the literature would suggest. Measurement of the sagittal diameter of the cervical spine in patients with chronic refractory epilepsy gives a useful indication of those at high risk of developing spinal cord injuries.

The authors wish to thank Dr JR Oxley (Chalfont Centre for Epilepsy) for his assistance, Dr HM Chapel (John Radcliffe Infirmary) for carrying out the tissue typing, Dr CG Woods (Nuffield Orthopaedic Centre) and Dr F Scaravilli (Institute of Neurology) for the pathological studies, Dr JR Rawstron (Wycombe General Hospital) for the biochemistry and Mrs R Fazakerley and Mrs C May for their help with typing.

\section{References}

1 Vasconcelos D. Compression fractures of the vertebrae during major epileptic seizures. Epilepsia 1973;14: 323-8.

${ }^{2}$ Pederson KK, Christiansen C, Ahlgren P, Lund M. Incidence of fractures of the vertebral spine in epileptic patients. Acta Neurol Scand 1976;54:200-3.

${ }^{3}$ Polatin P, Friedman MM, Harris MM, Horwitz WA. Vertebral fractures produced by metrazol-induced convulsions in treatment of psychiatric disorders. JAMA 1939;112:1684-7.

${ }^{4}$ Easton NL, Sommers J. The significance of vertebral fractures as a complication of metrazol therapy. $A m \mathrm{~J}$ Psychiatry 1942;98:538-43.

5 Worthing HJ, Kalinowsky LB. The question of vertebral fractures in convulsive therapy and in epilepsy. $A m J$ Psychiatry 1942;98:533-7.

${ }^{6} \mathrm{Wu}$ WQ, Fritzlen T. Subluxation of cervical spine in major epileptic seizure due to cerebral schistosomiasis. Surg Neurol 1976;5:333-5.

7 Agnetti V, Monaco F, Mutani R. Post-convulsive spinal epidural haematoma in ankylosing spondylitis. Eur Neurol 1979;18:230-3.

${ }^{8}$ Penning L. Functional pathology of the cervical spine. Amsterdam; Excerpta Medica Foundation 1968;95.

${ }^{9}$ Schneider RC, Papo M, Alvarex CS. The effects of chronic recurrent spinal trauma in high-diving. $J$ Bone Joint Surg 1962;44A:648-56.

${ }^{10}$ Bailey HL, Kato F. Paravertebral ossification of the cervical spine. Southern Med J 1972;65:189-92.

"Forestier J, Rotes-Querol J. Senile ankylosing hyperostosis of the spine. Ann Rheumat Dis 1950; 9:321-30.

12 Resnick D, Niwayama G. Radiographic and pathologic features of spinal involvement in diffuse idiopathic skeletal hyperostosis Radiology 1976;119:559-68.

${ }^{13}$ Forestier J, Lagier R. Ankylosing hyperostosis of the spine. Clin Orthop 1971;74:65-83.

14 Woodruff FP, Dewing SB. Fracture of the cervical spine in patients with ankylosing spondylitis. Radiology 1963;80:17-21.

15 Hunter T, Dubo H. Spinal fractures complicating ankylosing spondylitis. Ann Intern Med 1978;88:546-9.

${ }^{16}$ Corke CF. Spinal fracture and paraplegia after minimal trauma in a patient with ankylosing hyperostosis. $\mathbf{B r}$. Med J 1981;282:2035.

${ }^{17}$ Berkin CR, Hirson C. Hyperextension injury of the neck with paraplegia. J Bone Joint Surg 1954;36B:57-61.

${ }^{18}$ Barnes R. Paraplegia in cervical spine injuries. $J$ Bone Joint Surg 1948;30B:234-44.

19 Taylor AR, Blackwood W. Paraplegia in hyperextension cervical injuries with normal radiographic appearances. J Bone Joint Surg 1948;30B:245-8.

${ }^{20}$ Payne EE, Spillane JD. The cervical spine. An anatomico-pathological study of 70 specimens using a special technique with particular reference to the problem of cervical spondylosis. Brain 1957;38:571-96.

${ }^{21}$ Hashimoto I, Tak YK. The true sagittal diameter of the cervical spinal canal and its diagnostic significance in cervical myelopathy. J Neurosurg 1977;47:912-6.

${ }^{22}$ Alexander E, Davis $\mathrm{CH}$, Field $\mathrm{CH}$. Hyperextension injuries of the cervical spine. Arch Neurol Psychiatry 1958;79:146-50.

${ }^{23}$ Symonds $\mathrm{C}$. The interrelation of trauma and cervical spondylosis in compression of the cervical cord. Lancet 1953;1:451-4.

${ }^{24}$ Hardy AG. Cervical spinal cord injury without bony injury. Paraplegia 1977;14:290-305.

${ }^{25}$ Brill CB, Hartz WH, Mancall EL. Cervical disc herniation in the Gilles de la Tourette syndrome, Ann Neurol 981;9:311. 